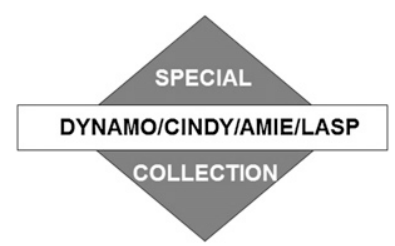

\title{
Balanced Dynamics and Moisture Quasi-Equilibrium in DYNAMO Convection
}

\author{
SHARON L. SESSIONS \\ Department of Physics, and Geophysical Research Center, New Mexico Institute of Mining and Technology, \\ Socorro, New Mexico \\ STIPO SENTIĆ \\ Climate and Water Consortium, New Mexico Institute of Mining and Technology, Socorro, New Mexico \\ DAVID J. RAYMOND \\ Department of Physics, and Climate and Water Consortium, New Mexico Institute of \\ Mining and Technology, Socorro, New Mexico
}

(Manuscript received 20 June 2018, in final form 13 June 2019)

\begin{abstract}
Tropical convection that occurs on large-enough space and time scales may evolve in response to large-scale balanced circulations. In this scenario, large-scale midtropospheric vorticity anomalies modify the atmospheric stability by virtue of thermal wind gradient balance. The convective vertical mass flux and the moisture profile adjust to changes in atmospheric stability that affect moisture and entropy transport. We hypothesize that the convection observed during the 2011 DYNAMO field campaign evolves in response to balanced dynamics. Strong relationships between midtropospheric vorticity and atmospheric stability confirm the relationship between the dynamic and the thermodynamic environments, while robust relationships between the atmospheric stability, the vertical mass flux, and the saturation fraction provide evidence of moisture adjustment. These results are important because the part of convection that occurs as a response to balanced dynamics is potentially predictable. Furthermore, the diagnostics used in this work provide a simple framework for model evaluation, and suggest that one way to improve simulations of large-scale organized deep tropical convection in global models is to adequately capture the relationship between the dynamic and thermodynamic environments in convective parameterizations.
\end{abstract}

\section{Introduction}

The Madden-Julian oscillation (MJO; Madden and Julian 1972) represents the most important source of intraseasonal variability in the tropics. Despite significant progress in theoretical models representing the MJO (e.g., Emanuel 1987; Neelin and Yu 1994; Raymond 2000, 2001; Sugiyama 2009a,b; Majda and Stechmann 2009; Sobel and Maloney 2012, 2013; Adames and Kim 2016; Raymond and Fuchs 2009; Fuchs and Raymond 2002, 2005, 2007, 2017), a basic understanding of the mechanisms governing convective organization at this scale remains a topic of debate. The purpose of this paper is to explore the possibility that the

Corresponding author: Sharon L. Sessions, sharon.sessions@ nmt.edu convective disturbances observed during the 2011 Dynamics of the Madden-Julian Oscillation (DYNAMO; Johnson and Ciesielski 2013a; Ciesielski et al. 2014a,b; Johnson et al. 2015) field campaign evolve in response to a large-scale balanced flow. We will evaluate DYNAMO observations with a set of diagnostics that quantify the coupling between the dynamics and thermodynamics that characterize the balanced dynamics framework. This framework complements existing theories of convective evolution observed during DYNAMO, and the corresponding diagnostics may be applied to evaluate models and improve convective parameterizations.

Whether or not tropical convection is a response to balanced dynamics or is primarily a consequence of stochastic processes is largely a matter of scale. Ooyama (1982) argued that balanced flow is important as long as the scale of the convective disturbance exceeds the 
Rossby radius. According to Ooyama, tropical disturbances greater than $O(1000) \mathrm{km}$, such as those observed during DYNAMO, are candidates by this criterion. Raymond et al. (2015) recast this in terms of time scales; if disturbances occur on time scales longer than those needed for the atmosphere to achieve balance, they evolve in response to balanced circulations. This criterion was also an explicit requirement in the derivation of a balanced dynamical theory for tropical convection based on weak temperature gradients (Sobel et al. 2001). We hypothesize that the convection observed during DYNAMO occurs on large-enough space and time scales that it evolves as a response to balanced dynamics. This is important since the part of convection that comprises a balanced response is potentially predictable (Raymond et al. 2015; Ying and Zhang 2017).

Convective organization in the middle latitudes is strongly constrained by balanced dynamics and upward motion is driven by strong horizontal temperature gradients. In the tropics, horizontal temperature gradients are weak (Charney 1963; Sobel and Bretherton 2000) so convection and radiative cooling become crucial processes in driving vertical motion, and the interplay between largescale balanced dynamics and thermodynamic constraints become fundamental to convective organization (Sobel et al. 2001; Raymond et al. 2015). In this paper, organization refers to the observed coherent regions of intense convective activity.

There are at least two proposed mechanisms by which balanced dynamics and thermodynamics intimately conspire to organize convection in the tropics. The first is "cooperative intensification" described by Ooyama (1982) in the context of tropical cyclones. In this paradigm, a deep large-scale horizontal rotation (primary circulation) drives a low-level inflow (frictional convergence) that fuels strong updrafts in the eyewall and an upperlevel outflow. The latent heat release associated with the convection (the secondary circulation) fuels an increase in vertical mass flux, which entrains midlevel air and further intensifies the vortex. Thus, thermodynamical processes in the secondary circulation are important for maintaining the primary circulation that drives the secondary circulation. According to Ooyama (1982), this mechanism is valid when the horizontal scale of the disturbance exceeds the Rossby radius of deformation. In principle, this spans nearly all scales excluding that of individual clouds. In practice, this is valid on scales in which the strong rotation constrains the internal hurricane dynamics.

Ooyama's cooperative intensification is one example of how convection interacts with balanced dynamics in the tropics. Raymond et al. (2015) described an alternate mechanism based on observations taken during the early stages of tropical cyclogenesis (Raymond et al. 2011; Raymond 2012; Gjorgjievska and Raymond 2014; Raymond et al. 2014, 2015). This paradigm begins with the presence of a midtropospheric potential vorticity $(\mathrm{PV})$ anomaly which induces a temperature dipole anomalywith cooling below a positive PV anomaly, and warming above-by virtue of thermal wind gradient balance. Convection then responds to the modified thermodynamic environment by adjusting the vertical mass flux and becoming relatively more bottom-heavy (Raymond and Sessions 2007; Gjorgjievska and Raymond 2014; Sessions et al. 2015, 2016). More importantly, the vertical gradient of vertical mass flux becomes larger at low levels, which by mass continuity, concentrates convergence near the lowest, moistest levels. This increases the column moisture and precipitation rate.

Both of these mechanisms involve relatively strong vorticity and moisture anomalies that are not present during the initial stages of the convective events observed during DYNAMO. Nevertheless, several studies have acknowledged the role of large-scale circulations in organizing the convection on this scale. For example, Pritchard and Bretherton (2014) identified causal evidence that rotational moisture advection is critical to simulating realistic MJOs in a superparameterized model. This result is consistent with the role of large-scale circulations in moistening by anomalous horizontal moisture advection identified by Maloney (2009), Kim et al. (2014), Zhu and Hendon (2015), and Adames and Wallace (2014, 2015). Large-scale circulations play a role in alternate theories for convective organization, including those based on frictionally driven convergence (Wang 1988; Seo and Wang 2010; Hsu and Li 2012), or boundary layer moisture convergence as a Kelvin-wave response (Wang and Rui 1990; Maloney and Hartmann 1998; Hsu and Li 2012). Here, we are concerned only with the convective-dynamical interactions, not with its application to the MJO or other large-scale circulations at this point. Furthermore, while our initial hypothesis was that DYNAMO convection evolved analogous to convection in cyclogenesis, our analysis revealed that this is not the case. Specifically, convection in DYNAMO responds differently to changes in atmospheric stability compared to cyclogenesis. We do not explore the reasons for this difference, but it does not invalidate the general hypothesis that convection evolves in response to balanced dynamics. To identify whether balanced dynamics is influencing convective evolution, we look for relationships between the large-scale dynamic and thermodynamic environments, and the convection using simple metrics.

The relationship between convection and the large-scale balanced flow involves an intricate interplay between 
the dynamics and thermodynamics. Raymond et al. (2015) identified "moisture quasi-equilibrium" as a predominant thermodynamic constraint. Moisture quasi-equilibrium is the mechanism by which the moist convective instability controls column moisture: convection adjusts to changes in the atmospheric instability; these changes modulate the import of environmental moisture, which controls the precipitation rate. Moisture quasi-equilibrium is identified by a strong relationship between atmospheric stability and moisture, and has been documented in observations (Raymond et al. 2011; Gjorgjievska and Raymond 2014; Raymond et al. 2014; Sentić et al. 2015) and models (Raymond and Sessions 2007; Sentić et al. 2015; Sessions et al. 2015, 2016; Raymond and Flores 2016). Given its central role in connecting the thermodynamic environment (specifically atmospheric stability) to column moisture, we explore the role of moisture quasi-equilibrium in DYNAMO convection.

Convection observed during DYNAMO has often been analyzed in the context of moisture mode theory (Raymond 2000; Sobel et al. 2001; Fuchs and Raymond 2002, 2005, 2007; Raymond and Fuchs 2007, 2009; Fuchs and Raymond 2017; Sugiyama 2009a,b; Sobel and Maloney 2012, 2013; Adames and Kim 2016). In moisture mode theory, precipitation associated with the convection is a sensitive function of atmospheric moisture. In environments with weak temperature gradients, the moisture dependence is often cast in terms of moist static energy or moist entropy, and the moisture mode instability occurs when the effective gross moist stability (GMS) is negative (Raymond and Fuchs 2007, 2009; Sobel and Maloney 2012, 2013; Adames and Kim 2016). In this work, we do not analyze convection in the context of moisture mode theory, but we note that the balanced dynamics hypothesis is consistent with moisture mode theory. Through balanced dynamics, the large-scale dynamics modifies the atmospheric stability which is strongly correlated with the atmospheric moisture via moisture quasi-equilibrium. This correlation is a consequence of horizontal moisture advection which controls the resulting precipitation rate, consistent with moisture mode theory. We assert that a complete description of DYNAMO-scale convection would include moisture mode theory, moisture quasi-equilibrium, and balanced dynamics. In this work, we focus on the latter components.

We hypothesize that the convection observed during DYNAMO is a response to large-scale balanced circulations, and that the related thermodynamic constraints govern the evolution of convection. We briefly describe the observational data in section 2 , then identify diagnostic signatures of balanced dynamics and moisture quasi-equilibrium in section 3. GMS is an important parameter for predicting the characteristics of convection from environmental conditions (Neelin and Held 1987; Raymond et al. 2015), and is recognized as valuable for characterizing the MJO. Furthermore, it is closely related to moisture quasi-equilibrium, so we also discuss GMS in section 3. Most of our results demonstrate correlations between diagnostics. By themselves, we cannot infer causality, however, in the context of the balanced dynamics theory, we make a case for causality after a brief summary of our results in section 4 . The response of the convective mass flux to changes in the atmospheric stability in DYNAMO convection is different from what is observed in cyclogenesis (Raymond et al. 2015). We discuss these differences and present a possible alternate mechanism that is relevant for disturbances in dry, lower vorticity environments in section 4 . We also discuss implications for model evaluation in section 4 .

\section{Data}

Diagnostic time series are calculated from the Colorado State University DYNAMO dataset, version $3 \mathrm{~b}$ (Ciesielski et al. 2014a,b; Johnson and Ciesielski 2013b; Johnson et al. 2015). In their dataset, the precipitation is obtained from the Tropical Rainfall Measuring Mission (TRMM) 3-hourly satellite data, the vertical component of the vorticity is calculated from $1^{\circ}$ gridded wind data, while the radiosonde profiles are obtained four to eight times per day depending on the station. Please refer to the above references for details on the dataset. The convective systems in the north sounding array (NSA) produced higher precipitation rates, thus we limit our analysis to this region.

Inoue and Back (2015a) recommended smoothing data on time scales larger than 1 day to filter out diurnal variations. We smooth the data with a 5-day moving average similar to Sobel et al. (2014) and Sentić et al. (2015) in order to focus on large spatial and temporal scales. Most results are presented as scatterplots between convective diagnostics. Each point in the scatterplots represents a daily average of the 5-day smoothed data.

To test if the vorticity variations produced by gridding the data in the DYNAMO dataset represent the largescale vorticity variations, we compared NCEP-NCAR FNL reanalysis data (NCEP 2000) to the gridded dataset (not shown). We find that the gridded data preserved the sign of variations in vorticity, but overestimate the strength for especially large values of the vorticity, by up to $50 \%$ compared to reanalysis. This overestimation is within the differences between versions $3 \mathrm{a}$ and $3 b$ of the DYNAMO datasets, and does not affect the qualitative relationships between diagnostic variables. 
Thus, our conclusions are robust in spite of the uncertainty in the magnitude of vorticity.

\section{Identifying signatures of balanced dynamics}

Figure 1 shows a time series of the precipitation rate observed in the NSA during the DYNAMO field campaign. Convective events are defined as continuous periods of rainfall exceeding $5 \mathrm{~mm}^{\text {day }}{ }^{-1}$ and are emphasized with gray shading. There were three major convective events observed during DYNAMO, each lasting roughly 10 days. This figure serves as a legend for the analysis that follows. Each event is identified by a different color and symbol; solid symbols indicate the developmental stages of the event while empty symbols represent the decay stages. The transition between development and decay is denoted by vertical lines (usually associated with the precipitation maximum). The periods between events are black in the time series data; the corresponding data associated with nonevents are indicated by gray bullets in the scatterplots. The beginning of each event is denoted by the respective symbol with a white bullet, while the last day of the event has a solid bullet (all symbols are shown in Fig. 1).

Figure 1 defines the convective events, but provides no clues to the mechanisms controlling these events or to the extent of their predictability. To assess this, we hypothesize that the convective events observed during DYNAMO evolve in concert with balanced dynamics and that the convection itself acts to maintain moisture quasi-equilibrium. If balanced dynamics plays a role in the convective life cycle, we expect correlations between the large-scale rotational environment (the primary circulation in the context of Ooyama 1982), atmospheric stability (which characterizes changes in the vertical temperature profile), and the vertical structure of convection (the secondary circulation). As in Ooyama (1982), we refer to the convection as the secondary circulation, not to be confused with the secondary circulation associated with geostrophic adjustment.

Large-scale circulations are associated with a PV anomaly in the midtroposphere. We do not investigate the origin of the PV anomaly in this work, however, there is evidence that it may come from the intrusion of extratropical Rossby waves (Ferranti et al. 1990; Ray and Li 2013; Zhao et al. 2013; Nasuno et al. 2015; Hall et al. 2017; Gahtan and Roundy 2019) or from equatorial circumnavigating modes (Maloney and Wolding 2015; Zhang et al. 2017; Chen and Zhang 2019). As an example of an external source, Nasuno et al. (2015) examined moistening processes that preceded the convective onset of convection observed during DYNAMO. They reported that off-equatorial Rossby wave trains encroached on the equatorial zone during

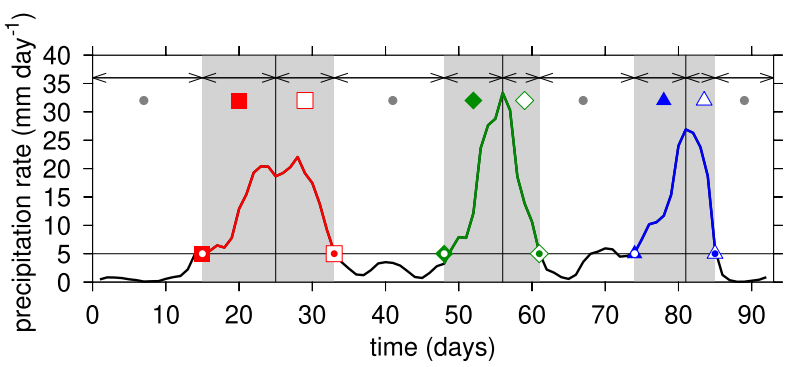

FIG. 1. Time series of NSA-averaged precipitation rate during DYNAMO. Data have been time smoothed with a 5-day running mean. The time is days since 1 Oct 2011. Convective events are defined as continuous periods of rainfall exceeding $5 \mathrm{~mm} \mathrm{day}^{-1}$ and are emphasized with gray shading; individual events are color coded and we have assigned symbols to individual events for the remaining figures. Solid symbols indicate developmental stages of the event; empty symbols indicate the decay phase of the event. White bullets over filled symbols represent the first day of each event; colored bullets over empty symbols denote the last day in the event. Gray bullets correspond to data taken during nonevents. Arrows along the top of the figure denote the time period for the developing and decaying stages of each event, as well as the periods between events, and are labeled with the corresponding symbol representing that stage in the data. The horizontal line shows the $5 \mathrm{~mm}$ day $^{-1}$ cutoff that defines the events, while the vertical lines denote the transition from developing to decaying stages of each event (usually identified by date of maximum precipitation).

the preconditioning of the first two events (they did not analyze the third event), which were accompanied by temperature dipole anomalies. It is possible that the convection itself contributes to PV circulations, at least during mature stages of development, but it does so on time scales that change the PV anomaly slowly compared to the convective time scale. Thus, convection remains under the influence of balanced dynamics.

The PV anomaly can exist even on the equator since relative vorticity can be nonzero when the planetary vorticity is zero. The balanced response of the thermodynamic environment-by virtue of the thermal wind relationship - is a (virtual) potential temperature dipole anomaly that modifies the atmospheric stability. This is illustrated in the top panel of Fig. 2. Convection responds to the changes in the atmospheric stability with an adjustment of the vertical mass flux. The nature of this response depends on the characteristics of the environment itself. For example, in moist environments with relatively large, positive PV anomalies at middle levels (i.e., conditions suitable for tropical cyclogenesis), the corresponding temperature anomaly (cooler at low levels and warmer aloft) increases atmospheric stability (though remains unstable to moist convection). Raymond and Sessions (2007) showed that this more stable environment develops convection that is more bottom-heavy, with the maximum in vertical mass flux shifting to lower 
Balanced dynamics and the thermodynamic environment

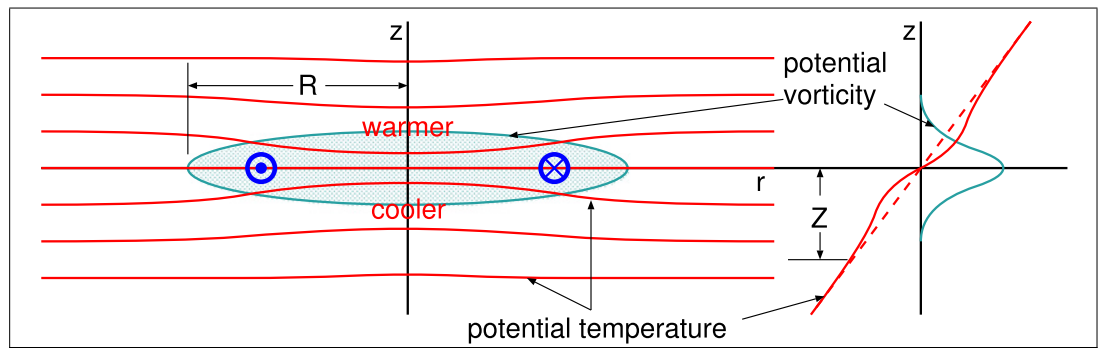

mid-level PV anomaly $\Leftrightarrow$ temperature dipole anomaly $\Leftrightarrow$ changes atmospheric stability (3-8 $\mathrm{km}$ average $\mathrm{PV})$

(instability index)

moisture quasi-equilbrium

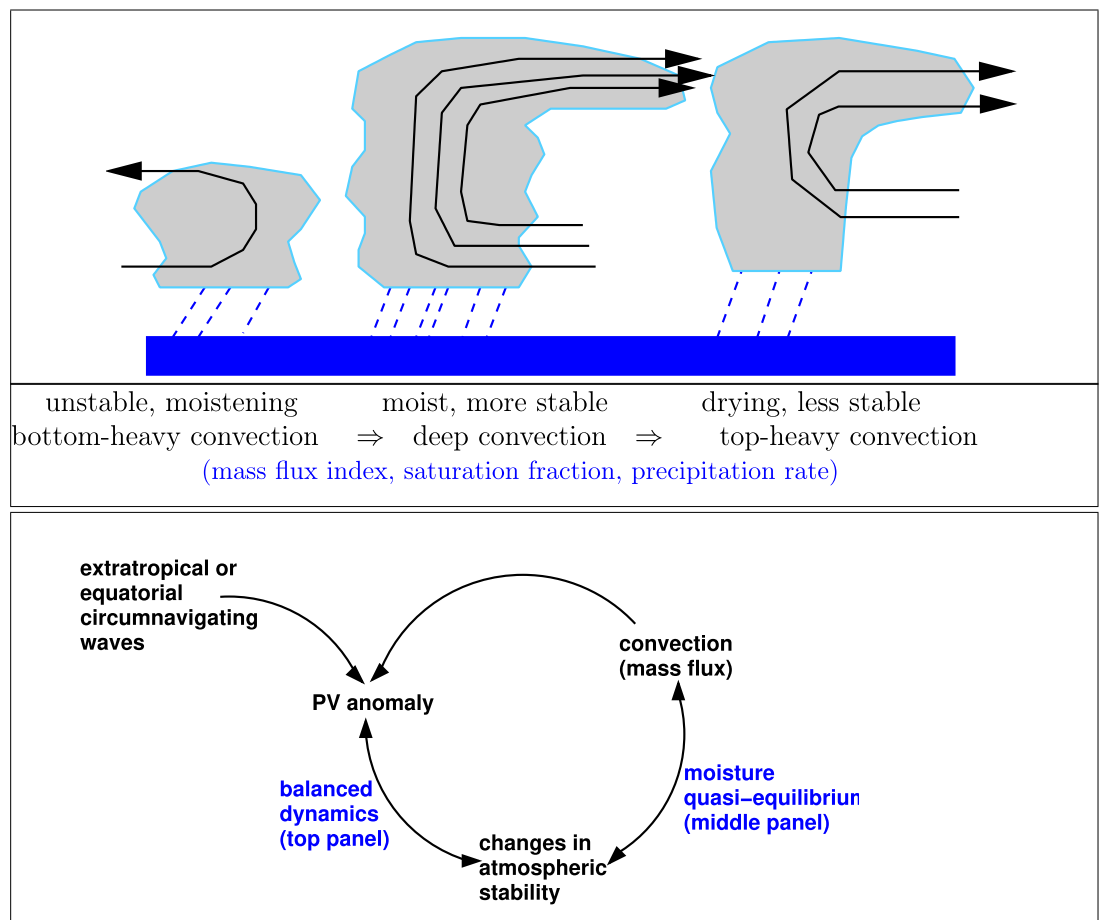

FIG. 2. (top) Balanced dynamics: The presence of a midlevel PV anomaly induces a potential temperature dipole anomaly that modifies the atmospheric stability. (middle) Convection adjusts to the changes in the atmospheric stability via changes in the vertical mass flux profile, which by mass continuity laterally entrains environmental air (black arrows). A correlation between the atmospheric stability, vertical mass flux, and the column moisture is evidence of moisture quasiequilibrium. Each component of this process is characterized by an observable: $3-8-\mathrm{km}$ average potential vorticity measures the strength of the primary circulation, an instability index quantifies the temperature dipole anomaly, a mass flux index quantifies the change in the convective profile related to the secondary circulation, while the saturation fraction and precipitation rate quantify the strength of the resulting convection. (bottom) Illustration showing how changes in the midtropospheric PV anomaly relate to changes in the atmospheric stability (balance dynamics) and how these in turn modulate convection (moisture quasi-equilibrium). Changes in the large-scale circulations may arise from external sources or from the convection itself.

levels. This occurs because parcels rising from the surface experience stronger buoyancy and thus accelerate through the cool anomaly, and decelerate at the warm anomaly creating a bottom-heavy profile.
More important than the lowering of the mass flux maximum is a significant increase in the vertical gradient of vertical mass flux in the lower troposphere which, by mass continuity, concentrates convergence 
at the lowest, moistest levels, and thus increases the precipitation rate.

Because the initial environment is so dry in the developing stages of convection observed during DYNAMO, initially moist parcels rise but quickly lose buoyancy as they entrain dry air. They deposit moisture and create conditions favorable to further development of deep convection. As described by Singh and O'Gorman (2013), parcels continue to rise in a progressively moistening environment, increasing the atmospheric stability (though remaining unstable to moist convection) until the saturation deficit is minimized (and saturation fraction is maximum). At this point, precipitating convection removes excess moisture which dries the atmosphere and reduces atmospheric stability. This process is illustrated in the middle panel of Fig. 2, and establishes the connection between the tropospheric temperature and moisture. The relationship between atmospheric stability and domain-mean moisture is mediated by changes in the convective mass flux profile and is a signature of moisture quasi-equilibrium. The bottom panel of Fig. 2 illustrates how these processes work together: a midtropospheric PV anomaly is accompanied by changes in the vertical temperature profile which changes the atmospheric stability (balanced dynamics). Convection responds to changes in the atmospheric stability via an adjustment of the vertical mass flux. By mass continuity, this controls the lateral entrainment of environmental air. Initially, the air is dry so convection moistens the environment; as entraining air moistens, convection deepens and the temperature profile becomes less unstable until the system reaches a maximum in the saturation fraction where further precipitating convection dries the environment. Moisture quasi-equilibrium encapsulates the relationship between atmospheric stability and column moisture. Throughout this process, convection modifies the large-scale dynamical circulations which continue the cycle.

To test the hypothesis that the convective events observed during the DYNAMO field campaign (Fig. 1) evolve consistent with balanced dynamics and moisture quasi-equilibrium, we consider four distinct tests that provide evidence that either supports or refutes our hypothesis:

1) a comparison of the balance and disturbed time scales;

2) a correlation between the midtropospheric PV anomaly and the atmospheric stability (which represents thermal wind gradient balance);

3) a correlation between atmospheric stability and the convection-specifically, identify whether convection maintains moisture quasi-equilibrium and exhibits the corresponding increase in precipitation rate; and
4) a correlation between the large-scale horizontal primary circulation and the vertical convective-scale secondary circulation, signifying a relationship between the large-scale dynamics and localized convection.

Each of these tests and their results are described below.

\section{a. Test 1: Balanced versus disturbance time scales}

According to the balanced dynamics hypothesis (Ooyama 1982; Sobel et al. 2001; Raymond et al. 2015), whether convection is a response to balanced flow or primarily a source of atmospheric vorticity is largely a matter of space and time scales. Here, we adopt the approach of Raymond et al. (2015) and compare the balanced time scale $t_{\text {balance }}$ to the disturbance time scale $t_{\text {disturbance. As }}$ argued in Raymond et al. (2015), if $t_{\text {disturbance }}>t_{\text {balance, }}$, then balance is established before the convection-related divergence modifies the vorticity. Thus, disturbances with $t_{\text {disturbance }}>t_{\text {balance }}$ are candidates for balanced responses, while disturbances with $t_{\text {disturbance }}<t_{\text {balance }}$ are dominated by stochastic processes and are considerably less constrained by large-scale circulations (and thus are less likely to be predictable).

As in Raymond et al. (2015), we define the balanced time scale by generalizing the Rossby number (Ro) to include relative vorticity $\zeta_{\text {rel }}$ so that the Coriolis parameter $f$ is replaced by the absolute vorticity $\zeta_{\text {abs: }}$ : $f \rightarrow \zeta_{\text {abs }}=f+\zeta_{\text {rel }}=f+\nabla \times \mathbf{v} \cdot \hat{\mathbf{k}}$, where $\mathbf{v}$ is the wind velocity and $\hat{\mathbf{k}}$ is a unit vector in the direction perpendicular to the Earth's surface. In this way, we can still have finite Rossby number on the equator where $f=0$. Replacing the typical horizontal wind speed $U$ and typical horizontal length scale $L$ by the corresponding time scale $T=L / U$, gives

$$
\mathrm{Ro}=\frac{U}{f L} \rightarrow \frac{U}{\zeta_{\mathrm{abs}} L}=\frac{1}{\zeta_{\mathrm{abs}} T},
$$

Setting Ro $=1$ as a critical value identifies a balanced time scale, $t_{\text {balance }}=1 / \zeta_{\text {abs. }}$. Because we are considering the role of a midlevel potential vorticity anomaly, we calculate $t_{\text {balance }}$ by averaging the absolute vorticity in a layer between 3 and $8 \mathrm{~km}$. The NSA extends from the equator to $10^{\circ} \mathrm{N}$, so $f$ is taken to be the average in this range, or the value at $5^{\circ} \mathrm{N}\left(f=1.27 \times 10^{-5} \mathrm{~s}^{-1}\right)$.

The time scale of the disturbance is given by the inverse of the absolute value of the divergence: $t_{\text {disturbance }}=$ $1 /|\nabla \cdot \mathbf{v}|$. There is a choice of which layer to average over in calculating the mean divergence. Since low-level inflow is associated with a midlevel vorticity anomaly, averaging over the $0-3-\mathrm{km}$ layer is a reasonable choice. Alternatively, averaging in the midtroposphere (3-8 km) provides a meaningful characteristic of the evolution of typical convection, with significant convergence or 
divergence at this level during the developing and decaying stages of the events.

Rather than plotting the actual time scales, Fig. 3 shows time series of the relative vorticity averaged over $3-8 \mathrm{~km}$ (red dashed line), and the divergence averaged between $0-3 \mathrm{~km}$ (solid blue line) and 3-8 km (black dashed line). In contrast to the majority of data which is presented with daily averages over a 5-day running mean, we plot daily averages with no smoothing for a more direct comparison. For convection responding to balanced circulations $t_{\text {disturbance }}>t_{\text {balance }}$ corresponds to $\left|\zeta_{\text {abs }}\right|>$ $|\nabla \cdot \mathbf{v}|$. We choose to plot these directly, without absolute values, to retain maximum information about the circulations. When the magnitude of the absolute vorticity exceeds the magnitude of the divergence (either low or midlevel), convection is likely responding to balanced dynamics. Note that Fig. 3 shows relative vorticity; the mean planetary vorticity $\left(f=12.7 \times 10^{-6} \mathrm{~s}^{-1}\right)$ in this region is shown with a horizontal dotted line. The sum of these greatly increases the absolute vorticity (and reduces the balanced time scale) so that convection is in the balanced regime.

\section{b. Test 2: PV and atmospheric instability}

The hypothesis that DYNAMO convection evolves as a response to balanced flow requires correlations between a midlevel PV anomaly and a potential temperature dipole anomaly as illustrated in Fig. 2. Thus, a straightforward and simple test of this hypothesis is to observe a relationship between the midlevel PV anomaly and a measure of changes in the atmospheric stability commensurate to changes in the vorticity anomaly.

The potential vorticity is defined (to satisfactory accuracy in the tropics) as

$$
\mathrm{PV}=\frac{1}{\rho} \zeta_{\mathrm{abs}} \frac{\partial \theta}{\partial z}=\frac{1}{\rho}\left(\zeta_{\mathrm{rel}}+f\right) \frac{\partial \theta}{\partial z},
$$

where $\rho$ is the density, $\theta$ is the potential temperature, and $z$ is altitude. As discussed in Raymond et al. (2015), weak temperature gradients imply that $\mathrm{PV}$ is proportional to $\zeta_{\text {abs}}$; a direct comparison (not shown) confirms this relationship. At the latitudes where DYNAMO observations were taken, and taking into consideration the weak temperature gradients in the tropical atmosphere, the PV anomalies arise from nonzero $\zeta_{\text {rel }}$. Thus, the midlevel PV anomalies are calculated as an average over a 3-8-km layer of the PV from the relative vorticity:

$$
\delta \mathrm{PV}=\frac{1}{\rho} \zeta_{\text {rel }} \frac{\partial \theta}{\partial z} .
$$

To determine the extent to which the midlevel PV anomaly influences the thermodynamic environment,

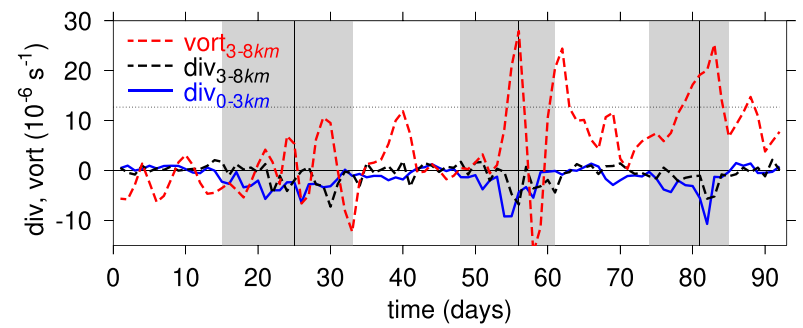

FIG. 3. Daily averages (no smoothing) of midtropospheric relative vorticity $\zeta_{\text {rel }}$ (dashed red line), low-level divergence $\nabla \cdot \mathbf{v}$ (solid blue line), and midlevel divergence (dashed black line). Gray shading denotes convective events, as identified in Fig. 1; vertical lines indicate transition from developing to decaying stages, coincident with the approximate precipitation maximum. When $\left|\zeta_{\text {abs }}\right|>|\nabla \cdot \mathbf{v}|$, the resulting organized convection is likely a response to balanced flow. Also, $\zeta_{\text {abs }}=\zeta_{\text {rel }}+f$, with $f=12.7 \times 10^{-6} \mathrm{~s}^{-1}$; including planetary vorticity (black dotted line) puts these disturbances in the balanced regime.

we quantify the potential temperature dipole anomaly with an instability index $\Delta s^{*}$ defined as (Raymond et al. 2011):

$$
\Delta s^{*}=s_{1-3 \mathrm{~km}}^{*}-s_{5-7 \mathrm{~km}}^{*},
$$

where $s_{1-3 \mathrm{~km}}^{*}$ and $s_{5-7 \mathrm{~km}}^{*}$ are the saturated moist entropies averaged over the 1-3- and 5-7-km layers, respectively. The saturated moist entropy $\left[s^{*}=c_{p} \ln \left(\theta_{e}^{*} / T_{R}\right)\right.$, with $c_{p}$ the specific heat of dry air at constant pressure, $\theta_{e}^{*}$ the saturated equivalent potential temperature, and $T_{R}=$ $300 \mathrm{~K}$ a reference temperature] is a function of temperature and pressure only, so this is an effective quantification of the changes in moist convective instability resulting from the temperature dipole anomaly (Fig. 2).

Although the layers we average over do not directly correspond to above and below the layer over which we measure the PV anomaly, we choose these values to be consistent with previous studies (e.g., Raymond et al. 2011; Sentić et al. 2015). Different ranges or metrics for measuring stability are qualitatively consistent (not shown).

Figure 4 shows a scatterplot of the instability index versus midlevel PV anomaly. Each symbol represents a daily average of the 5-day smoothed data. The shapes and colors of each symbol identifies the event it is associated with; as defined in Fig. 1, red squares represent event 1 , green diamonds represent event 2 , blue triangles represent event 3, and gray bullets represent data between events. Filled symbols correspond to development; open symbols correspond to the decaying stage of the events. The first day of each event is denoted by a solid symbol with a white bullet; the last day is denoted with an open symbol and colored bullet.

All three events show significant correlation between the instability index and the midlevel PV anomaly. 


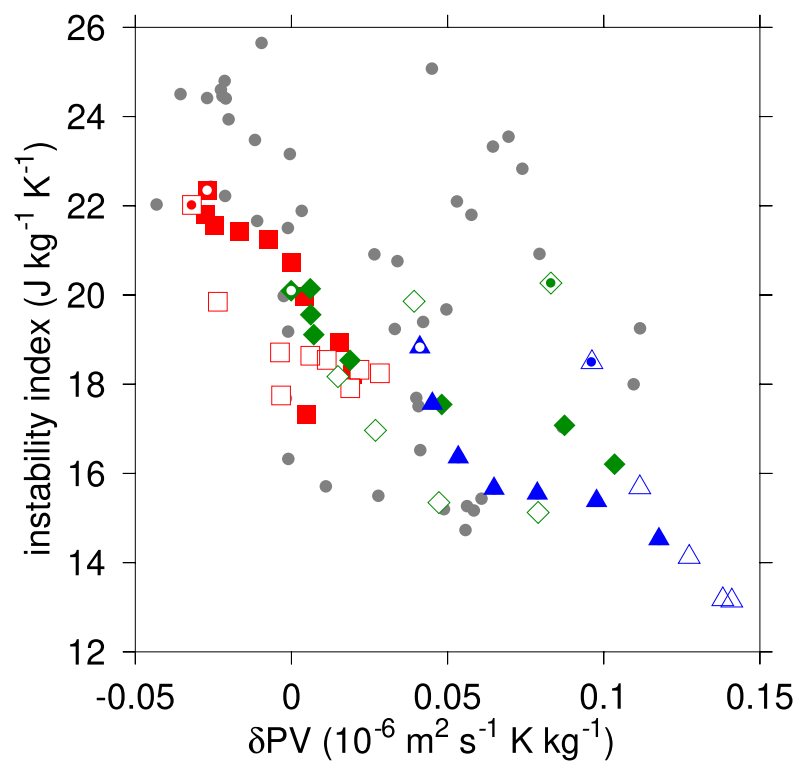

FIG. 4. PV anomaly averaged over the $3-8-\mathrm{km}$ layer vs the instability index; this illustrates the relationship between the largescale circulations and the atmospheric stability. Colors and symbols identify events. As defined in Fig. 1, event 1 is identified by red squares, event 2 by green diamonds, and event 3 by blue triangles. Filled symbols correspond to values prior to rainfall maximum; empty symbols indicate the event is decaying. Gray bullets correspond to daily averaged values for nonevents. White and colored bullets superposed on symbols indicate the first and last days of the events, respectively.

Note that in the developing stages of event 1 (solid red squares in Fig. 4), the PV anomaly is negative and is associated with the most unstable environments. As convection develops, the environment stabilizes (instability index decreases). For the other two events, the initial midlevel PV anomaly is positive but still associated with the most unstable environments. The gray bullets representing nonevents show weaker correlation between the instability index and the PV anomaly.

While scatterplots effectively illustrate correlations, they may obscure spatial and temporal evolution. To better illustrate the relationship between the evolution of the large-scale rotational environment and changes in the atmospheric stability, Fig. 5 shows time series of precipitation rate, $\mathrm{PV}$ anomalies, instability index, saturation fraction, GMS, and a mass flux index (MFI; saturation fraction, GMS, and MFI to be defined in the next section). To emphasize the relationship between the large-scale rotations and changes to atmospheric stability, compare the time series of the PV anomalies (Fig. 5a) and the instability index (Fig. 5b). During events (gray shading and bold lines), these are highly correlated, thus demonstrating the interplay between the dynamic and thermodynamic environments.

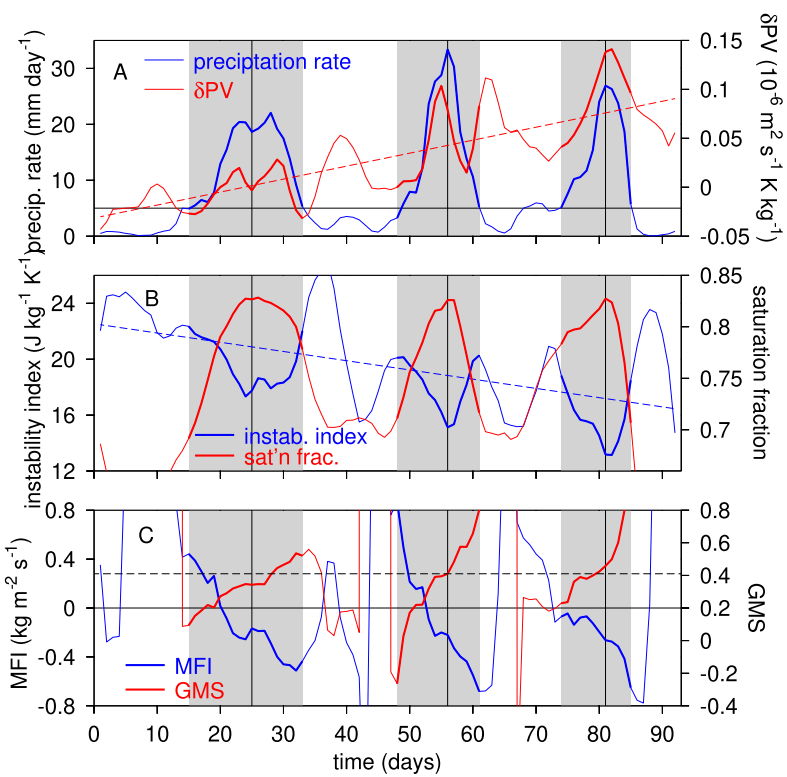

FIG. 5. Time series for (a) precipitation rate and PV anomalies (repeated from Figs. 1 and 3 for comparison), (b) instability index and saturation fraction, and (c) MFI and GMS. Each convective event is identified by gray shading and thick lines. The red dashed line in (a) is a linear fit to the PV anomalies; the blue dashed line in (b) is a linear fit for the instability index. The black dashed line in (c) is the critical GMS.

Note that the seasonal trend in the increased PV anomalies (denoted with the red dashed line in Fig. 5a) is mirrored by a decreasing trend in the instability index (blue dashed line in Fig. 5b). The relationship between the large-scale rotations and the atmospheric stability leaves little doubt that the dynamics and thermodynamics are strongly coupled. What remains to be shown is that convection evolves in response to changes in the atmospheric stability (next section).

\section{c. Test 3: Atmospheric stability, convection, and moisture quasi-equilibrium}

In the previous section, we demonstrated the expected relationship between the large-scale circulations and changes in the atmospheric stability. Convection responds to changes in the latter via a change in the vertical mass flux profile. This in turn influences the moisture in the column via horizontal advection (lateral entrainment) induced by mass continuity. In this section, we investigate the relationship between the atmospheric stability, the vertical mass flux profile, and the domain-mean moisture which encapsulates moisture quasi-equilibrium. The GMS (Neelin and Held 1987; Raymond et al. 2015) is another diagnostic quantity that quantifies the influence of the large-scale circulations on the convection, and has been established as important 

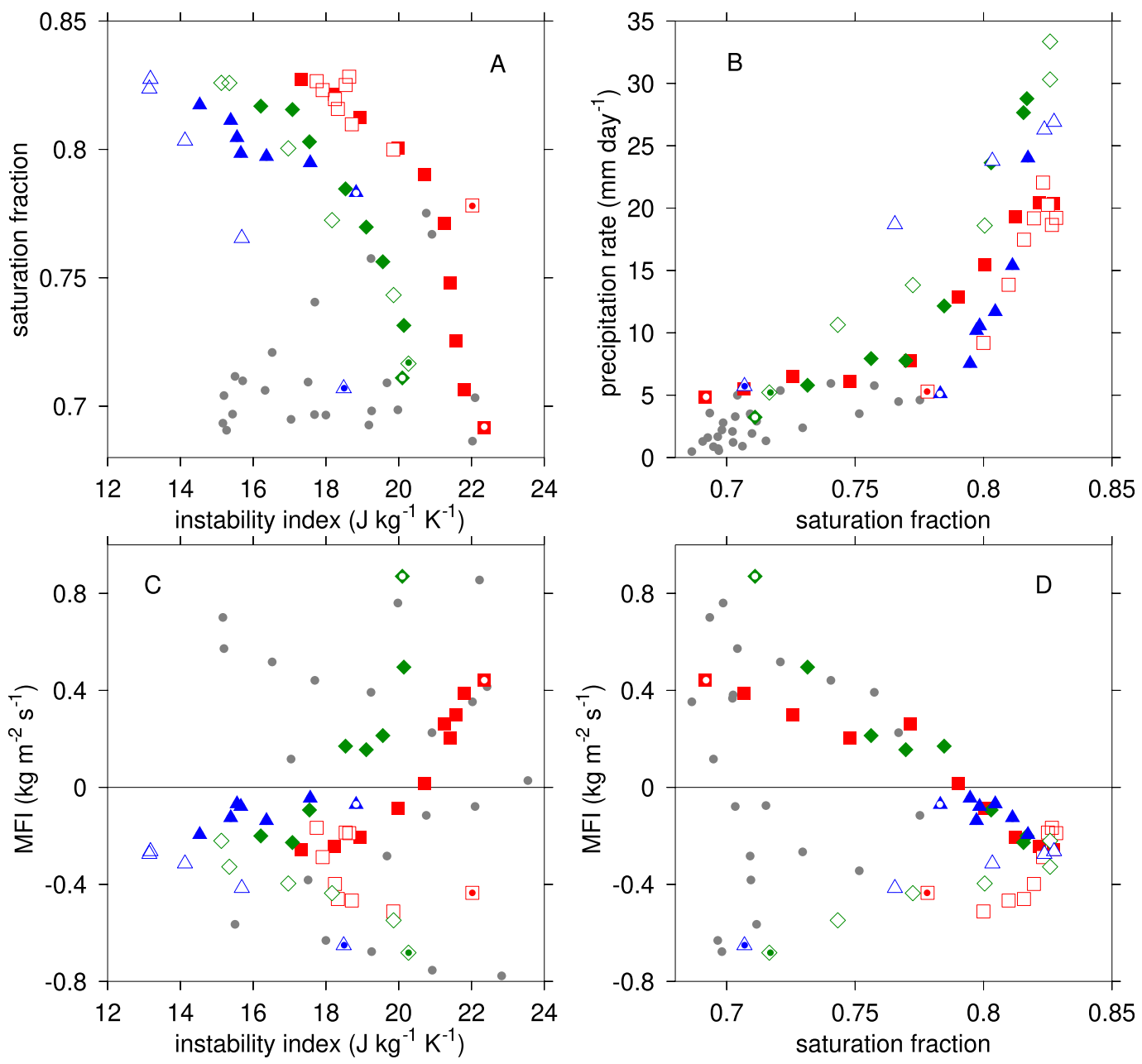

FIG. 6. (left) Relationship between atmospheric stability (quantified by the instability index) and (a) saturation fraction and (c) MFI. (right) Relationship between saturation fraction and (b) precipitation rate and (d) MFI. Symbols are defined in Fig. 1.

for diagnosing the MJO (e.g., Hannah and Maloney 2011, 2014; Pritchard and Bretherton 2014; Benedict et al. 2014; Masunaga and L'Ecuyer 2014; Raymond et al. 2015; Sentić et al. 2015; Inoue and Back 2015a,b, 2017). The evolution of GMS mirrors convective evolution associated with moisture quasi-equilibrium.

\section{1) Moisture QuASI-EQuiLIBRIUM}

To understand the relationship between the thermodynamic environment and the column moisture, consider a typical evolution of a convective event. If the environment is initially unstable to moist convection (with a corresponding high instability index), a buoyant plume will rise. As it rises, dry air is entrained and buoyancy decreases. How much it decreases depends on the saturation fraction of the environment (Singh and O'Gorman 2013). A dry environment (small saturation fraction) will halt ascent, evaporate any condensed moisture, and deposit that moisture into the atmosphere, thereby increasing the saturation fraction. Subsequent rising plumes will entrain moister and moister air until this process increases buoyancy via latent heating related to condensation. During this process, convection deepens as the environment stabilizes and moistens. The saturation fraction increases to a maximum corresponding to a minimum in the instability index.

The relationship between the instability index and saturation fraction observed during DYNAMO [reported previously in Sentic et al. (2015)] is shown in Figs. 5b and 6 a. We note that regardless of the relationship between the midlevel vorticity and instability index (Fig. 4), there is a strong correlation between the atmospheric stability and the domain mean moisture for all three events, where the more stable environments (characterized by smaller values of instability index) are also the moistest (highest saturation fractions). This relationship is 
evidence that DYNAMO convection maintains moisture quasi-equilibrium.

Consistent with other observational investigations (Bretherton et al. 2004; Peters and Neelin 2006; Raymond et al. 2007; Masunaga 2012; Sentić et al. 2015), high saturation fractions produce intense precipitation (Figs. 5a,b and $6 \mathrm{~b}$ ), suggesting that the precipitation rates in the intensely convective events are highly correlated with the changes in the vertical temperature profile (cf. precipitation rate and instability index in Figs. 5a,b) — regardless of the dynamical conditions and their influence on the thermodynamic environment.

\section{2) MASS FLUX RESPONSE TO INSTABILITY INDEX}

Moisture quasi-equilibrium can be identified by a strong correlation between the instability index and saturation fraction (Figs. 5b and 6a). This relationship depends on the response of the convection-the secondary circulation in the context of (Ooyama 1982) - to changes in atmospheric stability. We investigate this directly by considering the relationship between the instability index and changes in the vertical mass flux profile. To quantify the vertical mass flux (defined as $m_{\text {flux }}=\rho w$ with $w$ the vertical velocity), we define a mass flux index:

$$
\mathrm{MFI}=\left(\mathrm{sm}_{\mathrm{flux}}\right)_{3-5 \mathrm{~km}}-\left(\mathrm{sm}_{\mathrm{flux}}\right)_{7-9 \mathrm{~km}},
$$

where $\mathrm{sm}_{\text {flux }}$ is a scaled mass flux ( $m_{\text {flux }}$ divided by the $m_{\text {flux }}$ maximum), and the subscripts indicate the range of altitudes over which the averaged is computed. Positive values of MFI indicate more bottom-heavy convection, while negative values are indicative of top-heavy convection. A similar measure of bottom-heaviness defined by Raymond (2012) correlates strongly with the definition used here (not shown).

Recalling that solid symbols correspond to the developing phase of the convective events and empty symbols indicate decaying phases, Figs. $6 \mathrm{c}$ and $6 \mathrm{~d}$ show the relationships between the MFI and the instability index and saturation fraction. In the earliest stages of events 1 (red squares) and 2 (green diamonds), convection is initially bottom-heavy (MFI $>0$ ), and the atmosphere is unstable (high instability index, Fig. 6c) but very dry (saturation fractions near 0.7, Fig. 6d). As the environment moistens and becomes more stable, convection deepens until the saturation fraction reaches a maximum. At this point, the convective event has reached maturity (filled symbols become empty signaling the transition from development to decay), the instability index and saturation deficit are minimum, and deep convection evolves to top-heavy stratiform $(\mathrm{MFI}<0)$. The MFI continues to decrease as the instability index begins to increase. The third event (blue triangles) shows a similar evolution, but without a significant measure of bottom-heaviness in the early evolution. No obvious relationship exists during the periods between convective events (gray dots). The time series in Figs. 5b and 5c more directly shows the evolution of these quantities and their relationship to one another.

This evolution very closely follows the Singh and O'Gorman (2013) framework discussed in the previous subsection, and highlights the significance of the convective profile (and inferred lateral entrainment) in the moisture budget. However, the convective evolution differs significantly compared to that observed in tropical cyclogenesis. In the latter case, Raymond et al. (2014) used observations of tropical disturbances taken during the Tropical Cyclone Structure experiment (TCS08; Elseberry and Harr 2008) and the Pre-Depression Investigation of Cloud-Systems in the Tropics (PREDICT; Montgomery et al. 2012) to illustrate the relationship between the instability index and saturation fraction; their results are consistent with those in Fig. 6a. However, the high saturation fractions and low instability indices occurred in the middle stage of cyclogenesis when convection is bottom-heavy (Raymond et al. 2014); Figs. 6c and 6d suggest a different relationship. We discuss this apparent contradiction in section $4 \mathrm{c}$.

\section{3) GRoss MOIST STABILITY}

GMS (Neelin and Held 1987; Raymond et al. 2009) is a measure of export of moist entropy or moist static energy relative to the strength of convective activity (e.g., moisture convergence or import of dry static energy or dry entropy). It provides information about how convection responds to the large-scale flow, and variability in GMS is closely tied to variability in tropical convection (Back and Bretherton 2006; Masunaga and L'Ecuyer 2014; Inoue and Back 2015a), including convection observed during DYNAMO (e.g., Sobel et al. 2014). As pointed out in Raymond et al. (2015), predicting GMS as a function of local environmental conditions renders it a key element in predicting convection as a function of the large-scale flow.

In a careful analysis of the GMS calculated from observations taken during the Tropical Ocean and Global Atmosphere Coupled Ocean-Atmosphere Response Experiment (TOGA COARE), Inoue and Back (2015b) described the evolution of GMS relative to a critical value, $\mathrm{GMS}_{\text {critical }}$, and proposed several methods for calculating $\mathrm{GMS}_{\text {critical }}$, including the value of GMS at the precipitation maximum. In this context, they defined a "drying efficiency" $\Delta \Gamma$ equal to the difference between GMS and the critical GMS: $\Delta \Gamma=$ GMS - GMS critical $_{\text {. During }}$ the developing stages of convective events, GMS increases toward its critical value $(\Delta \Gamma<0$; environment is moistening). During the decaying stages, GMS continues to increase, but the drying efficiency becomes positive. This aligns with the moisture quasi-equilibrium 

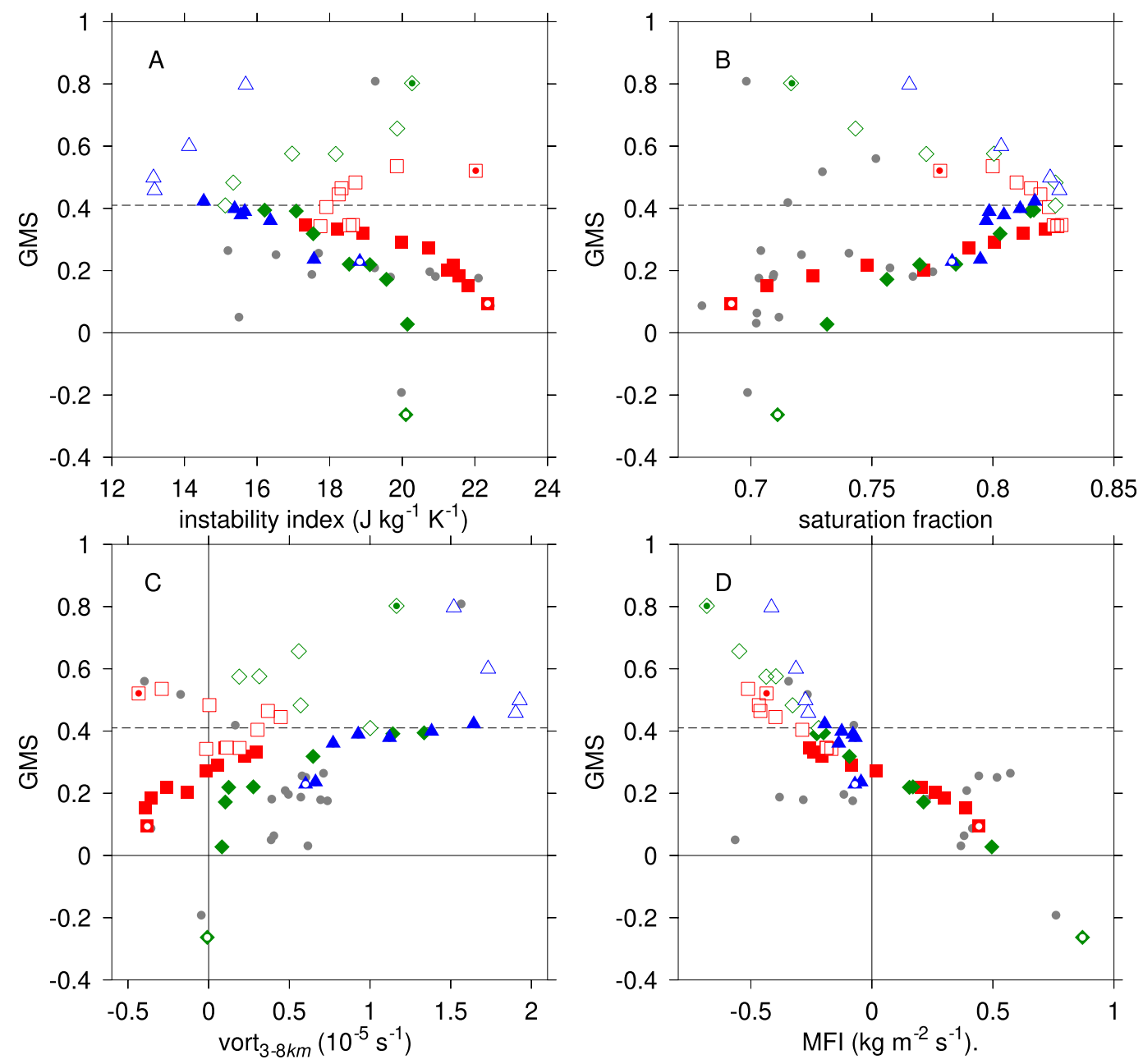

FIG. 7. GMS vs (a) instability index, (b) saturation fraction, (c) relative vorticity averaged in the 3-8-km layer, and (d) MFI. Symbols are defined in Fig. 1.

hypothesis: $\Delta \Gamma<0$ corresponds to moistening with the atmosphere becoming more stable with development, $\Delta \Gamma=0\left(\mathrm{GMS}=\mathrm{GMS}_{\text {critical }}\right)$ corresponds to the maximum stability and moisture for the thermodynamic environment, and subsequent increase in GMS $(\Delta \Gamma>0)$ corresponds to an atmosphere drying and becoming more unstable, in preparation for the next convective cycle.

Given its usefulness as a diagnostic in the convective system life cycle, we analyze how GMS varies in the context of balanced dynamics and moisture quasi-equilibrium. As in Sentić et al. (2015), and analogous to Sobel et al. (2014), we define GMS as the ratio of moist and dry entropy divergence:

$$
\mathrm{GMS}=\frac{\left\langle\omega \frac{\partial s}{\partial p}+\mathbf{v} \cdot \nabla s\right\rangle}{\left\langle\omega \frac{\partial s_{d}}{\partial p}\right\rangle}
$$

where $s$ and $s_{d}$ are the moist and dry entropies [defined analogously to $s^{*}$ in terms of potential temperature and equivalent potential temperature, after Eq. (4)], $\omega$ is the budget-derived vertical velocity in pressure coordinates, and $\mathbf{v}$ is the horizontal velocity. The angle brackets denote a vertical pressure integral from the surface to $100 \mathrm{hPa}$. As in Sentić et al. (2015) and Inoue and Back (2015a), the horizontal advection of dry static energy is neglected in the denominator.

Figure 5c shows the time evolution of GMS while Fig. 7 shows scatterplots of GMS as a function instability index, saturation fraction, the midlevel vorticity, and MFI. The dashed horizontal line in Fig. 5 and in each panel of Fig. 7 is the critical GMS, equal to 0.41 as reported in Sentić et al. (2015). The evolution of GMS very closely follows the evolution of the convective events as discussed thus far. Specifically, each convective event initially has a high instability index which decreases to a 
minimum value associated with the peak precipitation; a subsequent increase in the instability index coincides with decay of the event (Figs. 5b and 7a). As expected, GMS increases throughout this entire process, and the critical GMS coincides with the minimum in instability index. A similar pattern is observed with the relationship between GMS and saturation fraction (Figs. 5b,c and 7b): as convection develops, both GMS and saturation fraction increase until GMS reaches the critical value; at that point saturation fraction decreases as the system decays. The evolution of GMS is consistent with moisture quasi-equilibrium, and reflects the life cycle of GMS as described in Masunaga and L'Ecuyer (2014) and Inoue and Back (2017).

Figure $7 \mathrm{c}$ demonstrates the relationship between GMS and the midlevel vorticity associated with the primary circulation. It is interesting that, at least in the developing stages of the first event (and to some extent the development of all three events), GMS is correlated with the midlevel vorticity, suggesting that the large-scale primary circulation indeed plays a role in modulating the variability in convection as measured by this diagnostic. Figure $7 \mathrm{~d}$ provides evidence for how this happens: the GMS is determined by the shape of the vertical mass flux (quantified here by the MFI). In fact, the value of MFI that corresponds to the transition from development to decay nearly exactly corresponds to the critical value of GMS (as reported by Inoue and Back 2015b). This can also be seen in Fig. 5c, where the MFI and GMS during the convective events (gray shading) are highly anticorrelated. This is not surprising as most of the variance in the GMS is associated with the vertical advection of moist static energy (moist entropy in our case), and most of that is in turn related to variations in the vertical motion profile (Masunaga and L'Ecuyer 2014; Inoue and Back 2015a). Thus, predicting the GMS for a given set of environmental conditions is equivalent to identifying the impact of the environment on the vertical motion of convection. On the space and time scales associated with DYNAMO convection, balanced dynamics influence the convection (MFI), and thus the GMS.

\section{d. Test 4: Relationships between primary (midlevel $P V$ anomalies) and secondary circulation (convection)}

In this section, we consider the framework presented by Ooyama (1982), in which balanced dynamics involves the dynamical interplay between the large-scale primary circulation and a secondary circulation that characterizes the convective system. An important distinction between cooperative intensification described by Ooyama (1982) and the mechanism described here is that in a mature tropical cyclone, the secondary circulation associated with convection is driven by frictional convergence. In the case of larger-scale tropical disturbances such as those observed during DYNAMO, the convective vertical mass flux adjusts according to thermodynamic constraints; lateral entrainment of environmental air occurs as a consequence of these changes and mass continuity. This can occur through a deep layer in the troposphere, depending on the levels of the strongest vertical gradients in mass flux. So while the physical mechanisms coupling the primary and secondary circulations differ in mature cyclones compared to $O(1000)-\mathrm{km}$ disturbances, the interplay between dynamics and thermodynamics is fundamental to both: thermodynamics are key to mediating the coupling in both cases. If balanced dynamics are influencing the development of the convective system, we would expect to find correlations between the primary and secondary circulation.

We characterize the primary circulation by the midlevel (3-8-km average) relative vorticity, which is proportional to the midlevel PV anomaly [Eq. (2)] used in the previous section.

The secondary circulation (associated with the convection itself) can be characterized either by the vertical mass flux or from its divergence profile. We consider both here. The MFI, defined in Eq. (5), is a measure of the bottom-heaviness.

The divergence profile associated with the secondary circulation is quantified by the average divergence in the low $(0-3 \mathrm{~km})$, middle $(3-8 \mathrm{~km})$, and upper $(8-15 \mathrm{~km})$ troposphere. In the DYNAMO data, the low-level divergence is always negative (not shown), with strongest convergence at the precipitation maximum, while the upper-level divergence is always positive (not shown), with peak values coinciding with maximum precipitation rates. As expected, there is a strong correlation between MFI and the midlevel divergence (Fig. 8a): bottom-heavy convection (MFI > $0)$ occurs in tandem with divergence at midlevels, and as systems mature and become more top-heavy (MFI < 0), midlevel convergence (negative divergence) strengthens. The correlation weakens as the events decay since convergence weakens while the events remain top-heavy. Though weaker, this correlation holds even for nonevents (gray bullets). Given the strong correlation, it is sufficient to characterize the secondary circulation associated with convection by the MFI.

To identify whether the primary and secondary circulations are working in tandem, we look for correlations between the midtropospheric relative vorticity (which is proportional to the PV anomaly) and the MFI. This is shown in Fig. 8b. The correlation is robust in the 

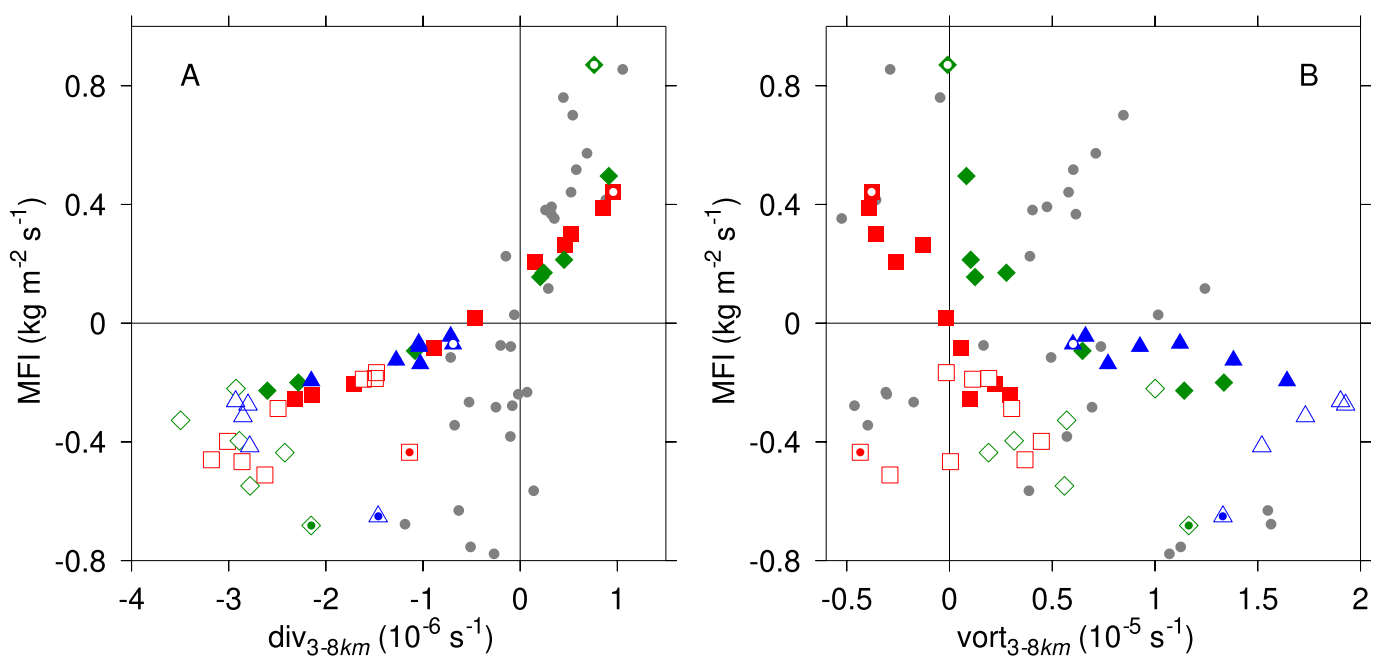

FIG. 8. (a) Midtropospheric divergence as a function of MFI, which demonstrates coherence of the secondary circulation. (b) MFI as a function of the midtropospheric vorticity as a measure of the relationship between the primary and secondary circulation. Symbols are defined in Fig. 1.

development of the first event (solid red squares), but somewhat weaker in the second and third events (green diamonds and blue triangles). We do not really know why this relationship varies from event to event, but we speculate that it is possibly a result of the influence of different atmospheric wave types existing within a given $\mathrm{MJO}$ event. For example, Yasunaga and Mapes $(2012 \mathrm{a}, \mathrm{b})$ characterized tropical waves according to whether they were "more rotational" or "more divergent." More rotational waves were lower frequency and more likely controlled by the moisture field, whereas more divergent wave types were higher frequency and more likely controlled by convective inhibition. They found that the MJO was modulated by both rotational and divergent waves.

In another study, Kikuchi et al. (2018) implemented a spatiotemporal wavelet transform to identify convective signatures of the different types of convectively coupled equatorial waves within the MJO envelop observed during DYNAMO. They found that while several wave types comprised convection within the MJO envelopes, slow convectively coupled Kelvin waves were the primary wave type present in all events. Analysis of the individual events showed that the first two events both had dominant Kelvin-wave signatures in the early stages, while the third had only weak Kelvinwave signatures, especially in contrast to a pronounced $n=1$ equatorial Rossby (ER) wave.

Regardless of the wave types contributing to the observed convective systems, recognizing the strong correlation between the large-scale rotations (midlevel PV anomalies), atmospheric stability, and precipitation rate (Figs. 5a,b) is important because these relationships may be enforced in models without full knowledge of the wave spectrum.

Another reason that the correlations between the primary and secondary circulations vary from event to event may be a consequence of contributions to precipitation that are independent of the midlevel vorticity. For example, Raymond and Flores (2016) developed a predictive model for rainfall based on environmental conditions. In addition to the instability index (which is related to the midlevel vorticity, Fig. 4), they found that surface moist entropy flux contributes significantly to the variance in precipitation.

\section{Summary and discussion}

In this paper, we examined observations taken during the 2011 DYNAMO field campaign to look for evidence that the major convective events evolved consistently with balanced dynamics, and that the resulting convection exhibits evidence of moisture quasi-equilibrium. In the remainder of this section, we summarize our results, discuss causality, compare these results with the evolution of convection during cyclogenesis, and consider implications of these results for model evaluation.

\section{a. Summary of results}

For convection that is a response to balance, the largescale rotational environment [primary circulation in the sense of Ooyama (1982)] modifies the thermodynamic environment, which in turn modifies the characteristics of convection (secondary circulation). Moisture quasi-equilibrium characterizes the relationship between 
atmospheric stability and the moisture which fuels convection. Balanced dynamics plays a major role in the evolution of convection for all three events observed during DYNAMO, as evidenced in the relationship between the midlevel PV anomaly and the instability index (Fig. 4) and coherence between the primary and secondary circulations (Fig. 8). There is also evidence for moisture quasi-equilibrium, demonstrated by the relationship between the instability index and saturation fraction [Fig. 6c, and also reported in Sentić et al. (2015)].

We considered four tests of the hypothesis that the convective events observed during the 2011 DYNAMO field campaign evolve consistent with balanced dynamics and moisture quasi-equilibrium. For all three events, we found that

1) the magnitude of absolute vorticity is greater than the divergence related to convection; consequently, $t_{\text {disturbance }}>t_{\text {balance }}$ and the events occur on time scales long enough to respond to balanced circulations (Fig. 3);

2) there is a strong correlation between the midlevel PV anomaly and the atmospheric stability, which is a consequence of thermal wind gradient balance (Figs. 4 and 5a,b);

3) convection responds to changes in the atmospheric stability by adjusting the mass flux profile, which modulates the moisture content via lateral entrainment driven by mass continuity. A relationship between the atmospheric stability and column moisture demonstrates the existence of moisture quasi-equilibrium (Figs. 5b and 6a), and the evolution is also consistent with the evolution of GMS (Figs. 5c and 7); and

4) there is coherence between the large-scale rotational environment (primary circulation) and the convection (secondary circulation) mediated by thermodynamic constraints (Fig. 8).

The correlations presented do not imply causality. However, we believe that changes in the large-scale dynamical environment cause the changes in the precipitation rate through balanced dynamics. In other words, given the large-scale circulations, we hypothesize that we can predict the precipitation rate based on the convective response to the changes in atmospheric stability induced by the circulations. We discuss this in the next section.

\section{$b$. The question of causality}

The balanced dynamics-moisture quasi-equilibrium paradigm asserts that a midtropospheric PV anomaly induces a thermodynamic response via the thermal wind relation (top panel of Fig. 2), the convection then responds to the changes in the thermodynamic environment via an adjustment in the mass flux profiles, which, via mass continuity, imports moist environmental air resulting in enhanced precipitation. The evidence presented in support of balanced dynamics and moisture quasi-equilibrium demonstrates correlations, not causality. However, we hypothesize that the convection evolves as a response to the changes in the pattern of potential vorticity. If this hypothesis proves correct, convection on the scales observed during DYNAMO is predictable from circulations that are typically resolved in global models.

There is considerable evidence for causality in this context. The first is that the convective time scale is much shorter than the balanced time scale (test 1, Fig. 3). Although the convection contributes to the large-scale vorticity anomalies, this contribution is over a longer time scale than the convective turnover time, so the convection itself is being modulated by the large-scale circulations.

Other evidence comes from numerical simulations. For example, using a cloud-resolving model (CRM) with the large-scale parameterized by the weak temperature gradient approximation (Sobel and Bretherton 2000; Raymond and Zeng 2005; Herman and Raymond 2014), Raymond and Sessions (2007) prescribed changes to the thermodynamic environment and found that convection became more bottom-heavy when the vertical profiles of potential temperature were more stable (with cooling at low levels and warming aloft). In these experiments [as well as similar ones in Sessions et al. $(2015,2016)$ ], convection responds to the changes in the thermodynamic environment and not vice versa.

In a similar framework, Sentić et al. (2015) incorporated temperature and moisture anomalies observed during DYNAMO into weak temperature gradient simulations. In these simulations, variations in vertical profiles of potential temperature were essential for reproducing the observed precipitation rate, saturation fraction, instability index, and GMS [though a similar study by Wang et al. (2013), found that surface fluxes and radiation were more important than temperature anomalies]. Thus, there is evidence that changes in the thermodynamic environment cause changes in convective mass flux, at least on the space and time scales considered here.

In another study, Pritchard and Bretherton (2014) demonstrated causal evidence that the existence of the simulated MJO is directly related to the horizontal moisture advection associated with tropical vorticity anomalies. Using a superparameterized global model, they showed that horizontal moisture advection associated with strong vorticity anomalies amplify the MJO, while weak anomalies produce no MJO. This is consistent with other studies which focus on the role of largescale circulations in initiating MJO-scale convection (Wang 1988; Wang and Rui 1990; Maloney and Hartmann 1998; Maloney 2009; Seo and Wang 2010; 
Hsu and Li 2012; Adames and Wallace 2014, 2015; Zhu and Hendon 2015).

Further studies have highlighted the role of the intrusion of extratropical Rossby waves (Ferranti et al. 1990; Ray and Li 2013; Zhao et al. 2013; Nasuno et al. 2015; Hall et al. 2017; Gahtan and Roundy 2019) or equatorial circumnavigating equatorial modes (Maloney and Wolding 2015; Zhang et al. 2017; Chen and Zhang 2019), all of which provide a source of midlevel rotational anomalies which have the potential to modify the atmospheric stability and thus influence the evolution of large-scale convective systems. This is true regardless of the source of the PV anomaly, as the balanced dynamics framework provides a mechanism by which the PV anomalies modulate convection at these scales.

Thus, several numerical studies have demonstrated causal evidence that large-scale rotations and corresponding changes in atmospheric stability modulate the convection and resulting precipitation rate. Other studies have highlighted the role of large-scale rotations in organizing tropical convection on this scale, all of which support our assertion that changes in convection are caused by changes in the large-scale circulation. Though the correlations by themselves do not imply causality, in the context of the balanced dynamics theory, they support the causality argument.

\section{c. Differences from cyclogenesis}

The hypothesis that DYNAMO convection evolves in response to balanced dynamics was inspired by observations and theories of tropical cyclogenesis (e.g., Raymond and Sessions 2007; Raymond et al. 2011; Gjorgjievska and Raymond 2014; Raymond et al. 2014). In this context, a midlevel vortex increases atmospheric stability (though the atmosphere remains unstable to moist convection), convection adjusts to the changes in the vertical temperature profile to become more bottom-heavy which imports moist environmental air at the lowest levels. This results in a higher precipitation efficiency associated with smaller values of GMS.

A puzzling difference between cyclogenesis and the DYNAMO observations is the relationship between atmospheric stability and the convective mass flux profile. The most stable environments observed in the early and middle stages of tropical cyclogenesis are associated with bottom-heavy convection. In contrast, the most stable environments (lowest instability index) observed during DYNAMO correspond to top heavy convection (Fig. 6c) with the highest saturation fractions (Figs. 6a,d) and precipitation rates (Fig. 6b). However, our results are consistent with TOGA COARE observations: LópezCarrillo and Raymond (2005) showed that the driest environments exhibited bottom-heavy mass flux profiles,

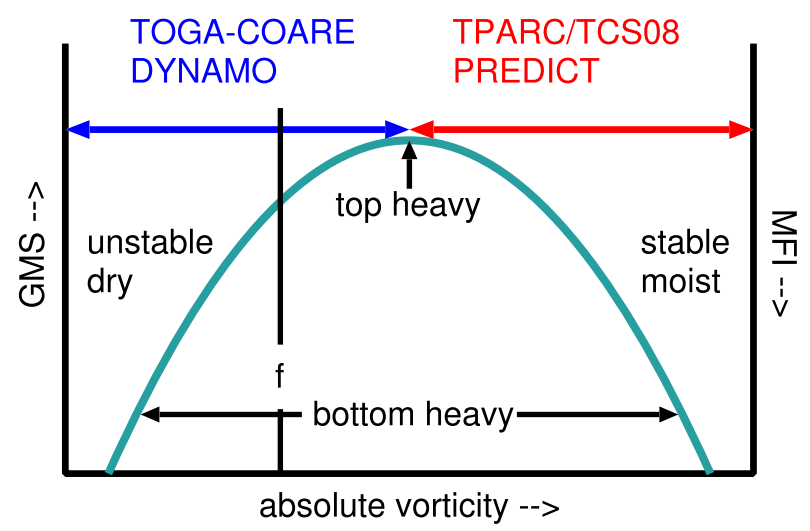

FIG. 9. Proposed regimes corresponding to contrasting relationships between atmospheric instability and GMS and between atmospheric instability and MFI on the MJO scale (TOGA COARE and DYNAMO) and during cyclogenesis (TPARC/TCS08 and PREDICT). In dry environments with low absolute vorticity, bottom-heavy convection (low GMS) corresponds to the most unstable environments. In contrast, bottom-heavy convection in moist, highly rotational environments is associated with more stable environments.

while the moistest environments supported deeper convection. Consistent with the present study, shallow convection in a dry environment moistened the environment, while stratiform convection resulted in a net drying. In terms of the diagnostics used in the present study, this would imply higher MFIs (i.e., bottom-heavy) would occur with the lowest saturation fractions, which is opposite of what is observed in cyclogenesis.

In cyclogenesis, the highest moisture and precipitation rates are associated with the smallest GMS and instability index (see, e.g., Raymond and Sessions 2007; Raymond et al. 2014); Fig. 15 in Raymond et al. (2014) shows a positive correlation between the instability index and GMS observed during THORPEX Pacific Asian Regional Campaign/Tropical Cyclone Structure 2008 (TPARC/TCS08) and PREDICT (Montgomery et al. 2012), and the smallest values of these correspond to the highest saturation fractions. In contrast, the smallest GMS values in DYNAMO exist in very dry environments (Fig. 7b), and the maximum moisture and precipitation rates occur when GMS is equal to its critical value (Inoue and Back 2015b).

Although we do not understand why these systems behave differently, it is possible that the convection on the MJO space and time scales occupies a different regime than convection in tropical cyclogenesis. Figure 9 illustrates a proposed regime separation in which accounts for the differences in the relationships between the atmospheric stability and GMS (or MFI, see Fig. 7) observed on the MJO scale (DYNAMO and TOGA COARE) and during cyclogenesis (TPARC/TCS08 and 
PREDICT). In both cases, GMS is inversely correlated with the MFI, but in dry environments with low absolute vorticity, bottom-heavy convection is associated with the most unstable environments. The bottom-heavy convection moistens the environment, which reduces both the saturation deficit and atmospheric instability. In contrast, bottom-heavy convection in moist, highly rotational environments is associated with higher atmospheric stability that is conducive to the development of a tropical cyclone.

One of the important differences between regimes is the initial saturation deficit of the environment which is large in DYNAMO, and much smaller in the womb of a nascent cyclone. In the former, bottom-heavy convection moistens the troposphere; in the latter, the troposphere is already moist and bottom-heavy profiles increase precipitation efficiency. Fully exploring these regimes is beyond the scope of this paper, but this provides a possible explanation for the differences observed in convective organization on the MJO scale compared to cyclogenesis.

\section{d. Implications}

The potential for predictability of tropical convection hinges on whether it occurs on time and space scales large enough to respond to large-scale balanced flows. According to Ooyama (1982), these scales must be $O(1000) \mathrm{km}$ in the tropics. There is evidence that the convection observed during DYNAMO evolves in response to large-scale balanced circulations. There is also evidence in European reanalysis (ERA-Interim) data that suggests the relationship between the dynamic and thermodynamic environments is robust: for example, Neena et al. (2017) show composites of vorticity and temperature anomalies from the related boreal summer intraseasonal oscillation (BSISO; the Northern Hemisphere summertime analog of the MJO). In these composites, the ERA-Interim data show a clear vorticity anomaly in the 500-700-hPa level, centered near $10^{\circ} \mathrm{N}$ (see Fig. 12 in Neena et al. 2017). There is also a temperature dipole anomaly with cooling below $500 \mathrm{hPa}$ and warming above, which spans from nearly $10^{\circ} \mathrm{S}$ to $10^{\circ} \mathrm{N}$ (Fig. 12 in Neena et al. 2017). Balanced dynamics provides a framework for understanding the interplay between the large-scale dynamics and convection, consequently, it may help improve predictability and provide a simple way to evaluate convective parameterizations.

As pointed out in Raymond et al. (2015), convection is potentially predictable if it occurs on space and time scales that respond to balanced flow. This has important implications for convective parameterizations since balanced flows occur on scales easily resolved by global models, and convection responding to those circulations must be consistent with diagnostic properties associated with balanced dynamics.

Ying and Zhang (2017) investigated predictability based on dynamical variables and found that the predictability increases with the scale of the phenomenon (with a possible practical predictability of 8 days for scales greater than $2000 \mathrm{~km}$ ). The part of convection that is a response to balanced dynamics is more easily parameterized than the part occurring on scales governed by stochastic processes. This suggests that the diagnostics used to identify signatures of balanced dynamics and moisture quasi-equilibrium may be used to evaluate convective parameterizations.

This framework could be applied to evaluate models in multimodel intercomparison projects. For example, Neena et al. (2017) compared composites of global circulation models (GCMs) that reproduced characteristics of the BSISO with high, medium, and low fidelity with composites derived from ERA-Interim data. Their Fig. 12 shows high- and medium-performing models have vorticity anomalies consistent with reanalysis (though the modeled anomalies extend nearly to the surface), and temperature dipole anomalies also consistent with the observed values. In contrast, poor-performing models had low-level vorticity anomalies and very weak temperature dipole anomalies. These results suggest that the coupling between the large-scale dynamics and thermodynamics via balanced dynamics is important for reproducing high-fidelity BSISOs (and MJOs). Thus, we posit the following hypothesis: models that do a good job reproducing characteristics of the MJO exhibit signatures of balanced dynamics and moisture quasi-equilibrium. Testing that hypothesis is left for future studies, but if it turns out to be true, this gives important clues for improving convective parameterizations. Specifically, one strategy would be to tune convective parameterizations so that the relationships between dynamics and thermodynamics are appropriately represented.

Acknowledgments. We thank Željka Fuchs, George Kiladis, Patrick Haertel, Mike Herman, and Larissa Back for helpful discussions, and three anonymous reviewers whose constructive comments helped to focus and improve this manuscript. SLS and SS acknowledge support from the Advanced Science Program at the National Center for Atmospheric Research. This work was supported by U. S. National Science Foundation Grants 1561084 and 1342001 . The data used in this study were collected as part of DYNAMO, which was sponsored by NSF, NOAA, ONR, DOE, NASA, and JAMSTEC. The involvement of the NSF-sponsored National Center for Atmospheric Research (NCAR) Earth Observing Laboratory (EOL) is acknowledged. The data are 
archived at the DYNAMO Data Archive Center maintained by NCAR EOL. Verification of the gridded vorticity data used data from NCEP (2000).

\section{REFERENCES}

Adames, A. F., and J. M. Wallace, 2014: Three-dimensional structure and evolution of the vertical velocity and divergence fields in the MJO. J. Atmos. Sci., 71, 4661-4681, https://doi.org/ 10.1175/JAS-D-14-0091.1.

- and — 2015: Three-dimensional structure and evolution of the moisture field in the MJO. J. Atmos. Sci., 72, 3733-3754, https://doi.org/10.1175/JAS-D-15-0003.1.

- , and D. Kim, 2016: The MJO as a dispersive, convectively coupled moisture wave: Theory and observations. J. Atmos. Sci., 73, 913-941, https://doi.org/10.1175/JAS-D-15-0170.1.

Back, L. E., and C. S. Bretherton, 2006: Geographic variability in the export of moist static energy and vertical motion profiles in the tropical pacific. Geophys. Res. Lett., 33, L17810, https:// doi.org/10.1029/2006GL026672.

Benedict, J. J., E. D. Maloney, A. H. Sobel, and D. M. W. Frierson, 2014: Gross moist stability and MJO simulation skill in three full-physics GCMs. J. Atmos. Sci., 71, 3327-3349, https:// doi.org/10.1175/JAS-D-13-0240.1.

Bretherton, C. S., M. E. Peters, and L. E. Back, 2004: Relationships between water vapor path and precipitation over the tropical oceans. J. Climate, 17, 1517-1528, https://doi.org/10.1175/ 1520-0442(2004)017<1517:RBWVPA > 2.0.CO;2.

Charney, J. G., 1963: A note on large-scale motions in the tropics. J. Atmos. Sci., 20, 607-609, https://doi.org/10.1175/1520-0469(1963) $020<0607$ :ANOLSM $>2.0 . \mathrm{CO} ; 2$.

Chen, X., and F. Zhang, 2019: Relative roles of preconditioning moistening and global circumnavigating mode on the MJO convective initiation during DYNAMO. Geophys. Res. Lett., 46, 1079-1087, https://doi.org/10.1029/2018GL080987.

Ciesielski, P. E., and Coauthors, 2014a: Quality-controlled upper-air sounding dataset for DYNAMO/CINDY/AIME: Development and corrections. J. Atmos. Oceanic Technol., 31, 741-764, https:// doi.org/10.1175/JTECH-D-13-00165.1.

- R. H. Johnson, K. Yoneyama, and R. K. Taft, 2014b: Mitigation of Sri Lanka island effects in Colombo sounding data and its impact on DYNAMO analysis. J. Meteor. Soc. Japan, 92, 385-405, https://doi.org/10.2151/jmsj.2014-407.

Elseberry, R. L., and P. A. Harr, 2008: Tropical cyclone structure (TCS08) field experiment science basis, observational platforms, and strategy. Asia-Pac. J. Atmos. Sci., 44, 209-231.

Emanuel, K., 1987: An air-sea interaction model of intraseasonal oscillations in the tropics. J. Atmos. Sci., 44, 2324-2340, https://doi.org/10.1175/1520-0469(1987)044<2324:AASIMO> 2.0.CO;2.

Ferranti, L., T. N. Palmer, F. Molteni, and E. Klinker, 1990: Tropical-extratropical interaction associated with the 30 60 day oscillation and its impact on medium and extended range prediction. J. Atmos. Sci., 47, 2177-2199, https://doi.org/ 10.1175/1520-0469(1990)047<2177:TEIAWT>2.0.CO;2.

Fuchs, Ž., and D. J. Raymond, 2002: Large-scale modes of a nonrotating atmosphere with water vapor and cloud-radiation feedbacks. J. Atmos. Sci., 59, 1669-1679, https://doi.org/10.1175/ 1520-0469(2002)059<1669:LSMOAN $>2.0$. CO; 2

— with radiative-convective instability and WISHE. J. Atmos. Sci., 62, 4084-4094, https://doi.org/10.1175/JAS3582.1.
—_, and —_, 2007: A simple, vertically resolved model of tropical disturbances with a humidity closure. Tellus, $\mathbf{5 9 A}$, 344-354, https://doi.org/10.1111/j.1600-0870.2007.00230.x.

$\longrightarrow$, and —, 2017: A simple model of intraseasonal oscillations. J. Adv. Model. Earth Syst., 9, https://doi.org/10.1002/ 2017MS000963.

Gahtan, J., and P. Roundy, 2019: Extratropical influence on 200-hPa easterly acceleration over the western Indian Ocean preceding Madden-Julian oscillation convective onset. J. Atmos. Sci., 76, 265-284, https://doi.org/10.1175/JAS-D-18-0069.1.

Gjorgjievska, S., and D. J. Raymond, 2014: Interaction between dynamics and thermodynamics during tropical cyclogenesis. Atmos. Chem. Phys., 14, 3065-3082, https://doi.org/10.5194/ acp-14-3065-2014.

Hall, N. M., S. Thibaut, and P. Marchesiello, 2017: Impact of the observed extratropics on climatological simulations of the MJO in a tropical channel model. Climate Dyn., 48, 25412555, https://doi.org/10.1007/s00382-016-3221-5.

Hannah, W. M., and E. D. Maloney, 2011: The role of moistureconvection feedbacks in simulating the Madden-Julian oscillation. J. Climate, 24, 2754-2770, https://doi.org/10.1175/ 2011JCLI3803.1.

— and - 2014: The moist static energy budget in NCAR CAM5 hindcasts during DYNAMO. J. Adv. Model. Earth Syst., 6, 420-440, https://doi.org/10.1002/2013MS000272.

Herman, M. J., and D. J. Raymond, 2014: WTG cloud modeling with spectral decomposition of heating. J. Adv. Model. Earth Syst., 6, 1121-1140, https://doi.org/10.1002/2014MS000359.

Hsu, P.-C., and T. Li, 2012: Role of the boundary layer moisture asymmetry in causing the eastward propagation of the MaddenJulian oscillation. J. Climate, 25, 4914-4931, https://doi.org/ 10.1175/JCLI-D-11-00310.1.

Inoue, K., and L. Back, 2015a: Column-integrated moist static energy budget analysis on various time scales during TOGA-COARE. J. Atmos. Sci., 72, 1856-1871, https://doi.org/10.1175/ JAS-D-14-0249.1.

— , and — - 2015b: Gross moist stability assessment during TOGA COARE: Various interpretations of gross moist stability. J. Atmos. Sci., 72, 4148-4166, https://doi.org/10.1175/ JAS-D-15-0092.1.

— , and — 2017: Gross moist stability analysis: Assessment of satellite-based products in the GMS plane. J. Atmos. Sci., 74, 1819-1837, https://doi.org/10.1175/JAS-D-16-0218.1.

Johnson, R. H., and P. E. Ciesielski, 2013a: Structure and properties of Madden-Julian oscillations deduced from DYNAMO sounding arrays. J. Atmos. Sci., 70, 3157-3179, https://doi.org/ 10.1175/JAS-D-13-065.1.

, and _ 2013b: Structure and properties of Madden-Julian oscillations deduced from DYNAMO sounding arrays. J. Atmos. Sci., 70, 3157-3179, https://doi.org/10.1175/JAS-D-13-065.1.

,,- J. H. Ruppert Jr., and M. Katsumata, 2015: Soundingbased thermodynamic budgets for DYNAMO. J. Atmos. Sci., 72, 598-622, https://doi.org/10.1175/JAS-D-14-0202.1.

Kikuchi, K., G. N. Kiladis, J. Dias, and T. Nasuno, 2018: Convectively coupled equatorial waves within the MJO during CINDY/DYNAMO: Slow Kelvin waves as building blocks. Climate Dyn., 50, 4211-4230, https://doi.org/10.1007/s00382-017-3869-5.

Kim, D., J.-S. Kug, and A. H. Sobel, 2014: Propagating versus nonpropagating Madden-Julian oscillation events. J. Climate, 27, 111-125, https://doi.org/10.1175/JCLI-D-13-00084.1.

López-Carrillo, C., and D. J. Raymond, 2005: Moisture tendency equations in a tropical atmosphere. J. Atmos. Sci., 62, 16011613, https://doi.org/10.1175/JAS3424.1. 
Madden, R. A., and P. R. Julian, 1972: Description of global-scale circulation cells in the tropics with a 40-50 day period. J. Atmos. Sci., 29, 1109-1123, https://doi.org/10.1175/15200469(1972)029<1109:DOGSCC > 2.0.CO;2.

Majda, A. J., and S. N. Stechmann, 2009: The skeleton of tropical intraseasonal oscillations. Proc. Natl. Acad. Sci. USA, 106, 84178422, https://doi.org/10.1073/pnas.0903367106.

Maloney, E. D., 2009: The moist static energy budget of a composite tropical intraseasonal oscillation in a climate model. J. Climate, 22, 711-729, https://doi.org/10.1175/2008JCLI2542.1.

_ , and D. L. Hartmann, 1998: Frictional moisture convergence in a composite life cycle of the Madden-Julian oscillation. J. Climate, 11, 2387-2403, https://doi.org/10.1175/1520-0442(1998) 011<2387:FMCIAC $>2.0$. CO;2.

__ , and B. O. Wolding, 2015: Initiation of an intraseasonal oscillation in an aquaplanet general circulation model. J. $A d v$. Model. Earth Syst., 7, 1956-1976, https://doi.org/10.1002/ 2015 MS000495.

Masunaga, H., 2012: Short-term versus climatological relationship between precipitation and tropospheric humidity. J. Climate, 25, 7983-7990, https://doi.org/10.1175/JCLI-D-12-00037.1.

__ , and T. S. L'Ecuyer, 2014: A mechanism of tropical convection inferred from observed variability in the moist static energy budget. J. Atmos. Sci., 71, 3747-3766, https://doi.org/ 10.1175/JAS-D-14-0015.1.

Montgomery, M. T., and Coauthors, 2012: The pre-depression investigation of cloud systems in the tropics (PREDICT) experiment. Bull. Amer. Meteor. Soc., 93, 153-172, https:// doi.org/10.1175/BAMS-D-11-00046.1.

Nasuno, T., T. Li, and K. Kikuchi, 2015: Moistening processes before the convective initiation of Madden-Julian oscillation events during the CINDY2011/DYNAMO period. Mon. Wea. Rev., 143, 622-642, https://doi.org/10.1175/ MWR-D-14-00132.1.

NCEP, 2000: NCEP FNL Operational Model Global Tropospheric Analyses, continuing from July 1999 (updated daily). Research Data Archive at the National Center for Atmospheric Research, Computational and Information Systems Laboratory, accessed 11 August 2018, https://doi.org/10.5065/D6M043C6.

Neelin, J. D., and I. M. Held, 1987: Modeling tropical convergence based on the moist static energy budget. Mon. Wea. Rev., 115, 3-12, https://doi.org/10.1175/1520-0493(1987)115<0003: MTCBOT $>2.0 . C O ; 2$.

— vective adjustment and the Madden-Julian oscillation. Part I: Analytic theory. J. Atmos. Sci., 51, 1876-1894, https://doi.org/ 10.1175/1520-0469(1994)051<1876:MOTVUC > 2.0.CO;2.

Neena, J. M., D. Waliser, and X. Jiang, 2017: Model performance metrics and process diagnostics for boreal summer intraseasonal variability. Climate Dyn., 48, 1661-1683, https://doi.org/10.1007/ S00382-016-3166-8.

Ooyama, K., 1982: Conceptual evolution of the theory and modeling of the tropical cyclone. J. Meteor. Soc. Japan, 60 , 369-379, https://doi.org/10.2151/jmsj1965.60.1_369.

Peters, O., and J. D. Neelin, 2006: Critical phenomena in atmospheric precipitation. Nat. Phys., 2, 393-396, https://doi.org/ 10.1038/nphys314.

Pritchard, M. S., and C. S. Bretherton, 2014: Causal evidence that rotational moisture advection is critical to the superparameterized Madden-Julian oscillation. J. Atmos. Sci., 71, 800-815, https:// doi.org/10.1175/JAS-D-13-0119.1.

Ray, P., and T. Li, 2013: Relative roles of circumnavigating waves and extratropics on the MJO and its relationship with the mean state.J. Atmos. Sci., 70, 876-893, https://doi.org/10.1175/ JAS-D-12-0153.1.

Raymond, D. J., 2000: Thermodynamic control of tropical rainfall. Quart. J. Roy. Meteor. Soc., 126, 889-898, https://doi.org/ 10.1002/qj.49712656406.

_- 2001: A new model of the Madden-Julian oscillation. J. Atmos. Sci., 58, 2807-2819, https://doi.org/10.1175/ 1520-0469(2001)058<2807:ANMOTM > 2.0.CO;2.

_- 2012: Balanced thermal structure of an intensifying tropical cyclone. Tellus, 64A, 19181, https://doi.org/10.3402/ tellusa.v64i0.19181.

_- , and X. Zeng, 2005: Modelling tropical atmospheric convection in the context of the weak temperature gradient approximation. Quart. J. Roy. Meteor. Soc., 131, 1301-1320, https://doi.org/10.1256/qj.03.97.

_- , and Ž. Fuchs, 2007: Convectively coupled gravity and moisture modes in a simple atmospheric model. Tellus, 59A, 627-640, https://doi.org/10.1111/j.1600-0870.2007.00268.x.

— tropical cyclogenesis. Geophys. Res. Lett., 34, L06811, https:// doi.org/10.1029/2006GL028607.

— oscillation. J. Climate, 22, 3031-3046, https://doi.org/10.1175/ 2008JCLI2739.1.

— , and M. M. Flores, 2016: Predicting convective rainfall over tropical oceans from environmental conditions. J. Adv. Model. Earth Syst., 8, 703-718, https://doi.org/10.1002/2015MS000595.

— S. L. Sessions, and Ž. Fuchs, 2007: A theory for the spinup of tropical depressions. Quart. J. Roy. Meteor. Soc., 133, 1743 1754, https://doi.org/10.1002/qj.125.

$\longrightarrow, \ldots$, A. H. Sobel, and Ž. Fuchs, 2009: The mechanics of gross moist stability. J. Adv. Model. Earth Syst., 1, 9, https://doi.org/ 10.3894/JAMES.2009.1.9.

,-- , and C. López-Carrillo, 2011: Thermodynamics of tropical cyclogenesis in the northwest Pacific. J. Geophys. Res., 116, D18101, https://doi.org/10.1029/2011JD015624.

— S. Gjorgjievska, S. Sessions, and Z. Fuchs, 2014: Tropical cyclogenesis and mid-level vorticity. Aust. Meteor. Ocean. J., 64, 11-25, https://doi.org/10.22499/2.6401.003.

_ Ž Ž. Fuchs, S. Gjorgjievska, and S. Sessions, 2015: Balanced dynamics and convection in the tropical troposphere. J. Adv. Model. Earth Syst., 7, 1093-1116, https://doi.org/ 10.1002/2015MS000467.

Sentić, S., S. L. Sessions, and Ž. Fuchs, 2015: Diagnosing DYNAMO convection with weak temperature gradient simulations. J. $A d v$. Model. Earth Syst., 7, 1849-1871, https://doi.org/10.1002/ 2015MS000531.

Seo, K.-H., and W. Wang, 2010: The Madden-Julian oscillation simulated in the NCEP Climate Forecast System Model: The importance of stratiform heating. J. Climate, 23, 4770-4793, https://doi.org/10.1175/2010JCLI2983.1.

Sessions, S. L., M. J. Herman, and S. Sentić, 2015: Convective response to changes in the thermodynamic environment in idealized weak temperature gradient simulations. J. Adv. Model. Earth Syst., 7, 712-738, https://doi.org/10.1002/2015MS000446.

- S. Sentić, and M. J. Herman, 2016: The role of radiation in organizing convection in weak temperature gradient simulations. J. Adv. Model. Earth Syst., 8, 244-271, https://doi.org/ 10.1002/2015MS000587.

Singh, M. S., and P. A. O'Gorman, 2013: Influence of entrainment on the thermal stratification in simulations of radiative-convective equilibrium. Geophys. Res. Lett., 40, 4398-4403, https://oi.org/ 10.1002/grl.50796. 
Sobel, A. H., and C. S. Bretherton, 2000: Modeling tropical precipitation in a single column. J. Climate, 13, 4378-4392, https://doi.org/10.1175/1520-0442(2000)013<4378:MTPIAS > 2.0.CO;2.

— work for modeling the Madden-Julian oscillation. J. Atmos. Sci., 69, 1691-1705, https://doi.org/10.1175/JAS-D-11-0118.1.

— tion of the MJO. J. Atmos. Sci., 70, 187-192, https://doi.org/ 10.1175/JAS-D-12-0189.1.

__ J. Nilsson, and L. M. Polvani, 2001: The weak temperature gradient approximation and balanced tropical moisture waves. J. Atmos. Sci., 58, 3650-3665, https://doi.org/10.1175/15200469(2001)058<3650:TWTGAA > 2.0.CO;2.

Sobel, A., S. Wang, and D. Kim, 2014: Moist static energy budget of the MJO during DYNAMO. J. Atmos. Sci., 71, 4276-4291, https://doi.org/10.1175/JAS-D-14-0052.1.

Sugiyama, M., 2009a: The moisture mode in the quasi-equilibrium tropical circulation model. Part I: Analysis based on the weak temperature gradient approximation. J. Atmos. Sci., 66, 15071523, https://doi.org/10.1175/2008JAS2690.1.

_ 2009b: The moisture mode in the quasi-equilibrium tropical circulation model. Part II: Nonlinear behavior on an equatorial $\beta$ plane. J. Atmos. Sci., 66, 1525-1542, https://doi.org/ 10.1175/2008JAS2691.1.

Wang, B., 1988: Dynamics of tropical low-frequency waves: An analysis of the moist Kelvin wave. J. Atmos. Sci., 45, 2051-2065, https://doi.org/10.1175/1520-0469(1988)045<2051:DOTLFW> 2.0.CO;2.

__ , and H. Rui, 1990: Dynamics of the coupled moist KelvinRossby wave on an equatorial $\beta$-plane. J. Atmos. Sci., 47,
397-413, https://doi.org/10.1175/1520-0469(1990)047<0397: DOTCMK $>2.0 . \mathrm{CO} ; 2$.

Wang, S., A. H. Sobel, and Z. Kuang, 2013: Cloud-resolving simulation of TOGA-COARE using parameterized large scale dynamics. J. Geophys. Res., 118, 6290-6301, https://doi.org/ 10.1002/JGRD.50510.

Yasunaga, K., and B. Mapes, 2012a: Differences between more divergent and more rotational types of convectively coupled equatorial waves. Part I: Space-time spectral analysis. J. Atmos. Sci., 69, 3-16, https://doi.org/10.1175/JAS-D-11-033.1.

, and - 2012b: Differences between more divergent and more rotational types of convectively coupled equatorial waves. Part II: Composite analysis based on space-time filtering. J. Atmos. Sci., 69, 17-34, https://doi.org/10.1175/ JAS-D-11-034.1.

Ying, Y., and F. Zhang, 2017: Practical and intrinsic predictability of multiscale weather and convectively coupled equatorial waves during the active phase of an MJO. J. Atmos. Sci., 74, 3771-3785, https://doi.org/10.1175/JAS-D-17-0157.1.

Zhang, F., S. Taraphdar, and S. Wang, 2017: The role of global circumnavigating modes in the MJO initiation and propagation. J. Geophys. Res. Atmos., 122, 5837-5856, https://doi.org/ 10.1002/2016JD025665.

Zhao, C., T. Li, and T. Zhou, 2013: Precursor signals and processes associated with $\mathrm{MJO}$ initiation over the tropical Indian Ocean. J. Climate, 26, 291-307, https://doi.org/10.1175/ JCLI-D-12-00113.1.

Zhu, H., and H. H. Hendon, 2015: Role of large-scale moisture advection for simulation of the MJO with increased entrainment. Quart. J. Roy. Meteor. Soc., 141, 2127-2136, https:// doi.org/10.1002/QJ.2510. 